\title{
Application of Simulation Methods in Cervical Spine Dynamics
}

\author{
Meng-Si Sun, ${ }^{1,2}$ Xin-Yi Cai, ${ }^{1,2}$ Qing Liu, ${ }^{1,2}$ Cheng-Fei Du $\mathbb{D}^{1,2}$ and Zhong-Jun Mo $\mathbb{D}^{3}$ \\ ${ }^{1}$ Tianjin Key Laboratory for Advanced Mechatronic System Design and Intelligent Control, School of Mechanical Engineering, \\ Tianjin University of Technology, Tianjin 300384, China \\ ${ }^{2}$ National Demonstration Center for Experimental Mechanical and Electrical Engineering Education, \\ Tianjin University of Technology, Tianjin 300384, China \\ ${ }^{3}$ Beijing Key Laboratory of Rehabilitation Technical Aids for Old-Age Disability, \\ Key Laboratory of Rehabilitation Technical Aids Technology and System of the Ministry of Civil Affairs, \\ National Research Centre for Rehabilitation Technical Aids, Beijing 100176, China
}

Correspondence should be addressed to Cheng-Fei Du; ddccffb31@hotmail.com and Zhong-Jun Mo; mozhongjun@nrcrta.cn

Received 15 February 2020; Revised 10 August 2020; Accepted 17 August 2020; Published 1 September 2020

Academic Editor: Costantino Del Gaudio

Copyright ( $\odot 2020$ Meng-Si Sun et al. This is an open access article distributed under the Creative Commons Attribution License, which permits unrestricted use, distribution, and reproduction in any medium, provided the original work is properly cited.

\begin{abstract}
Neck injury is one of the most frequent spine injuries due to the complex structure of the cervical spine. The high incidence of neck injuries in collision accidents can bring a heavy economic burden to the society. Therefore, knowing the potential mechanisms of cervical spine injury and dysfunction is significant for improving its prevention and treatment. The research on cervical spine dynamics mainly concerns the fields of automobile safety, aeronautics, and astronautics. Numerical simulation methods are beneficial to better understand the stresses and strains developed in soft tissues with investigators and have been roundly used in cervical biomechanics. In this article, the simulation methods for the development and application of cervical spine dynamic problems in the recent years have been reviewed. The study focused mainly on multibody and finite element models. The structure, material properties, and application fields, especially the whiplash injury, were analyzed in detail. It has been shown that simulation methods have made remarkable progress in the research of cervical dynamic injury mechanisms, and some suggestions on the research of cervical dynamics in the future have been proposed.
\end{abstract}

\section{Introduction}

The role of the human spine is to support the body and protect the spinal cord. Among all spinal injuries, cervical spine injuries are the most frequent and can be lifethreatening [1, 2]. Von Koch et al. [3] thought that neck injuries occupy $50 \%$ among all traffic injuries with heavy economic burdens. In the UK, soft tissue neck injuries cost more than $£ 1$ billion a year to insurance companies, accounting for the most percent of the cost of personal injury claims [4]. Cervical spine biomechanics have been concentrated on both experimental and computational investigation with the aim to determine thphysical properties of its parts for better risk assessment and have a better understanding of the cause of whiplash injuries. Regarding issues related to cervical spine disorders, volunteer experiments are rare, costly, and limited, while on the other hand, cadaveric experiments are not representative in most cases. The multibody (MB) and finite element (FE) methods which were as computational techniques have been roundly adapted to develop the dynamics of the cervical spine [5]. Computational models exert a profound influence on a wide range of dynamic loading conditions.

Several review investigations that concern the computational development of the cervical spine have already been published [6-10]. The first review on material properties and validation data of experiments for cervical spine models was summarized by de Jager [6]. Huelke and Nusholtz [7] reviewed on the reasons and biomechanics of cervical spine impact injuries and tolerances of clinical and laboratory research reports. Among other biomechanical models, Panjabi [8] simply summarized FE models of the neck. Yoganandan et al. [9] concentrated on the progress in the development of models (geometry), 
constitutive law identification, and model calibration, which is considered as the most important phase. Fagan et al. [10] reviewed the development of finite element analysis for spinal modelling.

Although in the recent years, numerous reviews on several aspects related to the cervical spine have been published [6-12], a few recent literature reviews have focused on the application of simulation methods in cervical spine dynamics. Therefore, as shown in Figure 1, this paper reviewed the improvement of simulation models including new modeling information, such as the details of IVDs, ligaments, and muscles in the recent years, and focused on the application of simulation models under different dynamic conditions including impact, ejection, and whiplash injury caused by the impact. At last, further research on simulation models is also discussed.

\section{Development of Simulation Models}

In the recent years, simulation methods have been broadly used in research concerning cervical biomechanics in order to help researchers gain a deep insight into the potential mechanisms of cervical spine injury and dysfunction. The most common simulation methods employ either $\mathrm{MB}$ models or finite element models. In this section, the structure, material properties, and advantages and disadvantages of different models will be briefly reviewed.

2.1. Multibody Models. MB dynamics is one of the most effective methods to study the response of the cervical spine in an accelerated condition [13]. Multi-rigid-body models, which are based on the MB dynamics theory, can be constructed easily, calculated quickly, and simulated the kinematics and dynamics of head-neck precisely. For this reason, $\mathrm{MB}$ models have been widely used to simulate the entire cervical spine [14]. Previous MB models of the cervical spine are summarized in Table 1 [15-31].

Over the past years, several studies on frontal and lateral collisions have been conducted. Williams and Belytschko [15] developed the first complicated head-neck model to characterize the behavior of the living body with the implementation of active muscle. Deng and Goldsmith [17] proposed a 3D model of the human head, neck, and upper torso with muscles, for predicting its motion for any specified initial conditions. The abovementioned model could also be used for comparison with the results of other investigators. To assess the behavior of passengers in the neck area of a car crash, De Jager et al. [19] built a neck model that can be applied to software MADYMO. Nevertheless, it is still limited in the model validation for rear-end collisions. Another detailed MB head-and-neck model was developed by Van Lopik and Acar [27], where the connections of linear actuators characterized both active and passive behaviors, which allowed muscles to curve along the vertebrae when the neck is bent.

The model of De Jager et al. [19] has been modified by many researchers. For example, Yamazaki et al. [22] used data of volunteer experiment to improve Jager's model.
More specifically, he modified the connection and bending properties of the whole vertebrae for increasing rigidity of the model and, then, used the model to investigate the influence of accelerations in different directions on the motion of cervical vertebrae. Moreover, the head and neck of Jager's global model were employed by Van den Kroonenberg et al. [21] in a MB rear-impact human-body model. The reactions of different severity conditions were compared approximately with volunteers and human cadavers. Nevertheless, at the time the study was conducted, the validation of that model was imperfect for lacking of available data of experiments. Van Der Horst [24] made modifications to Jager's detailed model, which was then implanted into the body model built in MADYMO. In that model, muscles were able to move along with the neck curvature, providing a more realistic muscle-force movement line.

In the rear-impact environment, head-neck models have made great improvements on the muscle and material. Jakobsson et al. [18] designed a MB model (C0-T1) to use in the sagittal plane; however, the time of the muscle reflexes was not taken into consideration [17]. Linder and Svensson [32] developed a mathematical model of neck rear impact that was used in the development of the BioRID dummy [33], an anthropometric test device. The neck was supplemented with two nonlinear stiffness muscle substitutes, which introduced a greater response than the available neck models at the time. Stemper et al. [26] defined both active and passive muscle properties in a head-neck model built in MADYMO. However, active muscle effects were not considered. Esat and Acar [34, 35] developed a novel MB model with extremely advanced material properties that can successfully reproduce the characteristic motion of the cervical spine with rear-end crash scenarios.

Considering the aeronautical field, Himmetoglu et al. [36] developed a biofidelic model with simple architecture, according to the anatomical parameters of the pilot in human dimensions of Chinese male pilot population, which could characterize the cooperation between the human body and the seat in rear collision for 50-percentile pilots. In the simulations, the established model was combined with a seat-helmet MB model and was validated through volunteer tests. It was demonstrated that the model could reveal the damage of head-neck during ejection.

2.2. Finite Element Models. Compared to MB models, FE models can offer more detailed information concerning local deformations and stress distribution; thus, stresses and strains in complicated structures, such as spinal bones and soft tissues, can be more veritably investigated. During the past 20 years, technology has progressed to such a point that more complicated three-dimensional finite element neck models with explicit geometries based on CT images have been developed and applied widely in the field of injury biomechanics, including impacts with different directions. CT plays an important role in the establishment of the finite element model. Not only the geometry but also the definition of the material properties could be derived from CT, in particular, for bone structures $[37,38]$. In tomography, 




Figure 1: Main aspects of the review.

TABLE 1: Overview of head-neck MB models.

\begin{tabular}{|c|c|c|c|c|c|c|c|}
\hline Year & Author & Type & Segment & IVD details & Ligament details & Muscle details & $\begin{array}{l}\text { Simulated impact } \\
\text { cases }\end{array}$ \\
\hline 1983 & $\begin{array}{l}\text { Williams and } \\
\text { Belytschko [15] }\end{array}$ & $\mathrm{MB}$ & $\mathrm{C} 1-\mathrm{T} 1$ & 6 DOF spring & Nonlinear springs & $\begin{array}{l}22 \text { pairs, active } \\
\text { (stretch-reflex) }\end{array}$ & Frontal-lateral \\
\hline 1984 & Merrill et al. [16] & $\mathrm{MB}$ & $\mathrm{C} 0-\mathrm{T} 1$ & $\begin{array}{l}6 \text { DOF spring/ } \\
\text { damper }\end{array}$ & - & 7 pairs, passive & Lateral-rear \\
\hline 1987 & $\begin{array}{c}\text { Deng and Goldsmith } \\
\text { et al. [17] }\end{array}$ & MB & $\mathrm{C} 1-\mathrm{C} 7$ & $\begin{array}{l}6 \text { DOF spring/ } \\
\text { damper }\end{array}$ & - & 13 pairs $(3 \mathrm{Pt})$, passive & Lateral-rear \\
\hline 1994 & Jakobsson et al. [18] & $\mathrm{MB}$ & $\begin{array}{l}\text { Human } \\
\text { body }\end{array}$ & - & - & Passive & Rear-end \\
\hline 1996 & De Jager et al. [19] & $\mathrm{MB}$ & $\mathrm{C} 0-\mathrm{T} 1$ & $\begin{array}{l}6 \text { DOF spring/ } \\
\text { damper }\end{array}$ & $\begin{array}{l}\text { Nonlinear } \\
\text { viscoelastic }\end{array}$ & 15 pairs, passive & Frontal-lateral \\
\hline 1997 & Camacho et al. [20] & $\mathrm{MB}$ & $\mathrm{C} 0-\mathrm{T} 1$ & $\begin{array}{l}3 \text { DOF spring/ } \\
\text { damper }\end{array}$ & - & - & Axial \\
\hline 1998 & $\begin{array}{c}\text { Van den Kroonenberg } \\
\text { et al. }[21]\end{array}$ & $\mathrm{MB}$ & $\begin{array}{l}\text { Human } \\
\text { body }\end{array}$ & - & - & Passive & Rear \\
\hline 2000 & Yamazaki et al. [22] & $\mathrm{MB}$ & $\mathrm{C} 0-\mathrm{T} 1$ & $\begin{array}{l}6 \text { DOF spring/ } \\
\text { damper }\end{array}$ & Spring element & 15 pairs, active (Hill) & Frontal-lateral \\
\hline 2000 & Linder et al. [23] & $\mathrm{MB}$ & $\mathrm{C} 0-\mathrm{T} 1$ & - & - & Muscle substitutes & Rear \\
\hline 2002 & Van Der Horst et al. [24] & $\mathrm{MB}$ & $\mathrm{C} 0-\mathrm{T} 1$ & $\begin{array}{l}6 \text { DOF spring/ } \\
\text { damper }\end{array}$ & Nonlinear cables & $\begin{array}{l}68 \text { pairs (multi } \mathrm{Pt}), \\
\text { active (Hill) }\end{array}$ & Frontal-rear \\
\hline 2004 & Lee et al. [25] & $\mathrm{MB}$ & $\mathrm{C} 0-\mathrm{T} 1$ & 6 DOF spring & Nonlinear Cables & $\begin{array}{l}22 \text { pairs (multi } \mathrm{Pt}) \text {, } \\
\text { active (Hill) }\end{array}$ & Frontal \\
\hline 2004 & Stemper et al. [26] & $\mathrm{MB}$ & $\mathrm{C} 0-\mathrm{T} 1$ & - & Nonlinear Cables & Passive & Lateral-rear \\
\hline 2004 & van Lopik et al. [27] & $\mathrm{MB}$ & $\mathrm{C} 0-\mathrm{T} 1$ & - & $\begin{array}{c}\text { Nonlinear } \\
\text { viscoelastic }\end{array}$ & Passive, active (Hill) & Frontal-rear \\
\hline 2009 & Himmetoglu et al. [28] & $\mathrm{MB}$ & $\begin{array}{l}\text { Human } \\
\text { body }\end{array}$ & $\begin{array}{l}\text { Massless spring/ } \\
\text { damper }\end{array}$ & $\begin{array}{l}\text { Massless spring- } \\
\text { damper }\end{array}$ & $\begin{array}{l}\text { Massless spring- } \\
\text { damper }\end{array}$ & Rear \\
\hline 2016 & Bruijn et al. [93] & $\mathrm{MB}$ & $\mathrm{C} 0-\mathrm{T} 1$ & Spring/damper & Nonlinear Cables & Passive & - \\
\hline 2017 & Cazzola et al. [94] & $\mathrm{MB}$ & $\begin{array}{l}\text { Human } \\
\text { body }\end{array}$ & - & - & MASI & Front \\
\hline 2018 & Mortensen et al. [95] & MB & $\mathrm{C} 0-\mathrm{T} 1$ & - & - & MASI & Lateral \\
\hline
\end{tabular}

DOF = degrees of freedom; Hill = Hill muscle model; $\mathrm{Pt}=$ points; IVD = intervertebral disk; MASI = Musculoskeletal model for the Analysis of Spinal Injuries.

different tissues of the head and neck have different gray values because of their different densities. Mimics threshold segmentation is to separate and extract the corresponding tissues by using different gray values. To analyze the subtle biomechanical changes of the vertebral body, the CT valuebased material property assignment method can be taken into consideration. Several scholars [39-41] reported that CT value-based material property assignment could offer more details than the traditional homogeneous assignment method. Those details could reflect the anisotropic biological characteristics of different bones. We import the model into the Mimics and choose the empirical formula we need, the materials of the vertebrae were assigned according to the formulas in Mimics, and the CT values were divided accordingly to distinguish the differences between different bones $[42,43]$. The FE method has been widely adopted in 
the research of spine biomechanics, relating to clinical treatment [44-48], dynamic impact, and so on [13, 49]. A full summary of previous FE spine models can be found in Table 2.

The first FE model of the full cervical spine was modeled by Kleinberger [50]. This model incorporated the intervertebral disc and spinal ligaments, but lacked any representation of the musculature. In addition, materials of all were regarded as isotropic linear elastic, which is not sufficient for representing a majority of biological tissues. Dauvilliers et al. [51] developed a neck model taking into account the passive action of the muscle and confirming the stiffness features of the soft tissues. The vertebrae and head were regarded as rigid bodies, while the tissues between vertebrae were modeled with brick and spring elements. In 1998, Yang et al. [52] constructed a more complex anatomical head-neck FE model, where linear elastic-plastic materials for the vertebrae and linear viscoelastic materials for IVDs could be hit in the axis direction of front and postimpact.

Deng et al. [53] developed a FE model which was one of the most advanced cervical spine models at the time. More specifically, this was the first FE tissue model based on fundamental tissue properties rather than calibrated or assumed ones. It incorporated nonlinear viscoelastic material models to represent tissues under dynamic conditions. Another novelty of Deng's model was to include active muscle characteristics using the Hill muscle model, where the muscles were represented using two spring elements to allow for realistic muscle-force estimation when the neck was flexed. The model developed by Halldin et al. [64] was the first FE cervical spine model that detailed the upper cervical spine complex and incorporated some modelling techniques used in spinal segment modelling, such as the use of a composite annulus fibrosus. Active muscle response was added to this model by Brolin et al. [65].

In 2003, Yang and Yao [55] established the first cervical FE biomechanical model, which has been widely used in the automobile safety field in China, where the neck model was connected with a rigid dummy head (based on the Hybrid III 50th percentile dummy head form) to simulate and verify front collision. Two years later, Yang et al. [66] developed a head model which included skull and brain. The neck model established in 2003 was modified and coupled with the head model to simulate and verify front and rear impact. However, the geometric data of both models were purchased by the Viewpoint Company in the United States. At the same time, Eggers et al. [57] made some necessary changes to Yang's model [52], taking into account the compression and lateral bending of the cervical spine, and the ligament was considered as nonlinear. The lateral impact response of the head and neck, as well as the damage to the upper part of the cervical vertebra, was investigated. Then, the model was simulated to assess the response of soft tissue in frontal collisions.

Meyer et al. [56] proposed a detailed FE neck model of a human volunteer and conducted an original model validation against experimental data recorded using the same volunteer. The temporal validation of the optimized model in the frequency domain demonstrated that adjusting the mechanical properties on the temporal response alone is not enough to ensure bio-faithful behaviour. The next year, Zhang et al. [1] developed a detailed C0-C7 FE model according to the precise geometries of a cadaveric specimen. A validation study was performed by simulating the model response under different typical loading conditions. Fice et al. [57] focused on a precise geometric and material representation at the tissue level to build a more representative FE model, which included more advanced ligament material properties [67]. As shown in Figure 2, the vertebrae geometries were in good agreement with the published anthropometry and were modeled as rigid bodies for computational efficiency. The intervertebral discs were constructed with solid elements for the annulus fibrosus ground substance and nucleus pulposus and layers of shell elements representing the fiber lamina (Figure 2(b)). The facet joints were represented with a superior and inferior layer of solid elements for the articular cartilage and a squeeze-film model to simulate the synovial fluid (Figure 2(c)). Ligaments were modeled using multiple 1D nonlinear rate-dependent tension-only spring elements. In addition, ligament relaxation was determined using an optimized method developed by Cronin et al. [60] to better predict neck kinematics and tissue level response.

Gender differences have been testified to be an significant cause for the occurrence of lasting whiplash-associated disorders (WAD). In particular, women are twice as likely as men on average to have sustaining symptoms and are more at risk under similar crash conditions [68, 69]. Consequently, Östh et al. [70] set up an average female FE model with ligaments for evaluating the rear-end collision biomechanics. Later, the model was combined with soft tissues to develop the head-and-neck model [61].

\section{Applications}

3.1. Impact. A number of studies on the response of the impact have been carried out, including dynamic responses of the neck, such as the neck load, angle of rotation, and acceleration, studied using multi-rigid-body models, as well as the analysis of local biomechanical responses and neck damage mechanisms, such as ligament elongation and intervertebral disc stresses, using finite element models based on human body anatomy (this part will be discussed in detail in Section 3.3).

The different responses to impact are affected by different impact accelerations. Zhang et al. [71] compared the predicted rotations, peak disc stresses, and ligament strains of each motion segment during whiplash, with and without acceleration exerted on the C7 inferior surface. Mustafy et al. [72] used a biofidelic model of the cervical functional spinal unit to compare the spinal load distribution under pure compression and sagittal flexion or extension at two different impact rates. Lee et al. [73] predicted changes in biomechanical parameters, including intradiscal pressure, dynamic stiffness, endplate region stresses, and the spine shock-absorbing mechanism under different impact durations or loading rates and investigated the relation between 
TABle 2: Overview of FE head-neck models.

\begin{tabular}{|c|c|c|c|c|c|c|c|}
\hline Year & Author & Type & Segment & IVD details & Ligament details & Muscle details & $\begin{array}{c}\text { Simulated } \\
\text { impact cases }\end{array}$ \\
\hline 1993 & Kleinberger [50] & $\mathrm{FE}$ & $\mathrm{C} 0-\mathrm{T} 1$ & Isolinear IVD & Isolinear solid element & - & Frontal-axial \\
\hline 1994 & $\begin{array}{l}\text { Dauvilliers } \\
\text { et al. [51] }\end{array}$ & $\mathrm{FE}$ & $\mathrm{C} 0-\mathrm{T} 1$ & Linear composite & Linear spring/dampers & Passive & Frontal-lateral \\
\hline 1998 & Yang et al. [52] & FE & $\mathrm{C} 0-\mathrm{T} 1$ & $\begin{array}{c}\text { Isolinear AF, } \\
\text { viscoelastic NP }\end{array}$ & $\begin{array}{l}\text { Linear cables and } \\
\text { membranes }\end{array}$ & Passive & Axial-lateral \\
\hline 1999 & Deng et al. [53] & $\mathrm{FE}$ & $\mathrm{C} 0-\mathrm{T} 1$ & $\begin{array}{l}\text { Isolinear AF, } \\
\text { viscoelastic NP }\end{array}$ & $\begin{array}{l}\text { Linear viscoelastic } \\
\text { membranes }\end{array}$ & 15 pairs, active (Hill) & Frontal \\
\hline 2000 & $\begin{array}{l}\text { Halldin and } \\
\text { Brolin [54] }\end{array}$ & FE & $\mathrm{C} 0-\mathrm{T} 1$ & Linear comp AF (shell) & Bilinear cables & 14 pairs, active (Hill) & $\begin{array}{c}\text { Frontal- } \\
\text { lateral-axial }\end{array}$ \\
\hline 2003 & Yang and Yao [55] & $\mathrm{FE}$ & $\mathrm{C} 1-\mathrm{C} 7$ & $\begin{array}{l}\text { Isolinear AF, } \\
\text { viscoelastic NP }\end{array}$ & Spring elements & $\begin{array}{c}\text { Hughes-Liu element, } \\
\text { active }\end{array}$ & Frontal \\
\hline 2004 & Meyer et al. [56] & $\mathrm{FE}$ & $\mathrm{C} 0-\mathrm{T} 1$ & $\begin{array}{c}\text { Isolinear IVD (AF and } \\
\text { NP) }\end{array}$ & Nonlinear cables & Solid elements, passive & $\begin{array}{l}\text { Frontal- } \\
\text { lateral-rear }\end{array}$ \\
\hline 2005 & Fice et al. [57] & $\mathrm{FE}$ & $\mathrm{C} 0-\mathrm{T} 1$ & $\begin{array}{c}\text { Isolinear AF, } \\
\text { viscoelastic NP }\end{array}$ & $\begin{array}{l}\text { Nonlinear tension-only } \\
\text { membrane }\end{array}$ & - & Lateral \\
\hline 2006 & Zhang et al. [1] & $\mathrm{FE}$ & $\mathrm{C} 0-\mathrm{C} 7$ & $\begin{array}{c}\text { Isolinear AF, Isolinear } \\
\text { NP }\end{array}$ & Nonlinear cables & - & Rear \\
\hline 2008 & $\begin{array}{c}\text { Toyota Motor } \\
\text { Corporation [58] }\end{array}$ & $\mathrm{FE}$ & $\begin{array}{l}\text { Human } \\
\text { body }\end{array}$ & - & $\begin{array}{l}\text { Nonlinear tension-only } \\
\text { membrane }\end{array}$ & Passive & Rear \\
\hline 2011 & Panzer et al. [59] & $\mathrm{FE}$ & $\mathrm{C} 0-\mathrm{C} 7$ & $\begin{array}{l}\text { Solid hexahedral } \\
\text { elements }\end{array}$ & $\begin{array}{c}\text { Tension-only beam } \\
\text { elements }\end{array}$ & $\begin{array}{l}25 \text { pairs, passive, active } \\
\text { (Hill) }\end{array}$ & Frontal \\
\hline 2011 & Fice et al. [57] & $\mathrm{FE}$ & $\mathrm{C} 0-\mathrm{C} 7$ & Solid elements & $\begin{array}{l}\text { Nonlinear tension-only } \\
\text { spring elements }\end{array}$ & $\begin{array}{l}25 \text { pairs, passive, active } \\
\text { (Hill) }\end{array}$ & Rear \\
\hline 2014 & Cronin et al. [60] & $\mathrm{FE}$ & $\mathrm{C} 0-\mathrm{C} 7$ & $\begin{array}{c}\text { Isolinear AF, Isolinear } \\
\text { NP }\end{array}$ & $\begin{array}{l}\text { Nonlinear axial } \\
\text { elements }\end{array}$ & Passive-active (Hill) & Rear \\
\hline 2016 & Östh et al. [61] & $\mathrm{FE}$ & $\mathrm{C} 0-\mathrm{C} 7$ & $\begin{array}{l}\text { Hexahedral elements } \\
\text { and orthotropic } \\
\text { quadrilateral }\end{array}$ & $\begin{array}{l}\text { Orthotropic membrane } \\
\text { elements }\end{array}$ & Hill muscle & Rear \\
\hline 2017 & Hassan et al. [62] & $\mathrm{FE}$ & $\begin{array}{c}\text { Human } \\
\text { body }\end{array}$ & Shell and brick elements & $1 \mathrm{D}$ elements & 1-D and brick elements & Rear \\
\hline 2018 & Jiayi et al. [63] & $\mathrm{FE}$ & $\mathrm{C} 0-\mathrm{C} 7$ & Isotropic linear elastic & $\begin{array}{l}\text { Isotropic linear elastic } \\
\quad \text { (incompressible) }\end{array}$ & $\begin{array}{c}\text { Passive (the Ogden } \\
\text { model of superelastic } \\
\text { materials) }\end{array}$ & $\begin{array}{l}\text { Arrested } \\
\text { landing }\end{array}$ \\
\hline
\end{tabular}

$\mathrm{AF}=$ annulus fibrosus; $\mathrm{NP}=$ nucleus pulposus; $\mathrm{DOF}=$ degrees of freedom; Hill = Hill muscle model; $\mathrm{Pt}=$ points; $\mathrm{IVD}=$ intervertebral disk .

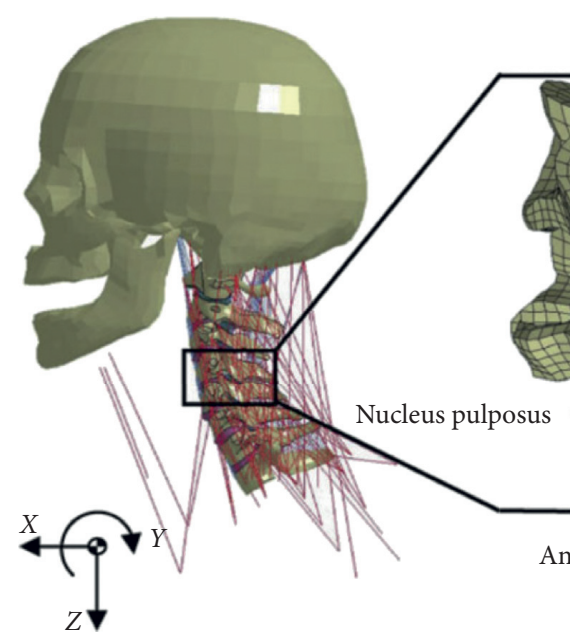

(a) (b)

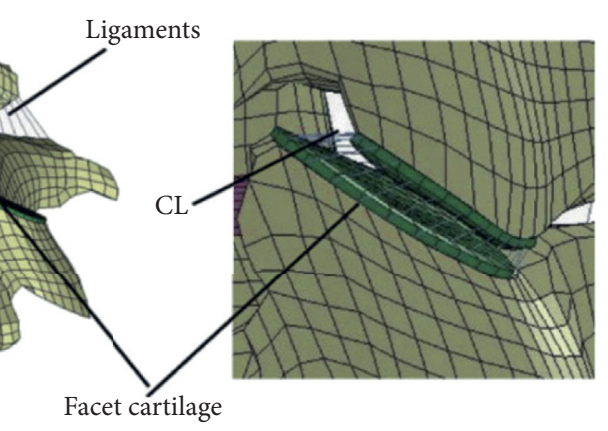

(Adapted from Fice et al. 2011)

(c)

Figure 2: (a) Whole cervical spine model, (b) sectioned isometric view of the C4-C5 segment model, and (c) lateral close up of the C4-C5 facet joint. (Figure 2 is reproduced from Jason (B) [57] (under the creative commons attribution license/public domain)). 
the loading rate and vertebral body fracture potential. White et al. [74] proposed an approach where the loading conditions from the simulations are fed into intervertebral disc FE models, which contribute to generating more realistic loading conditions. Hedenstierna et al. [75] investigated the distribution of neck muscle loads during impacts with different directions. The computed data, such as peak crosssectional forces and effective strain distributions, were compared to experimental electromyography (EMG) data.

The models mentioned above indicated that the resistance of the whole spine to impact load depends on the loading rate and direction. In all spinal components where loads were applied, the load distribution of neck muscles was affected by load direction and the stress increased with the loading rate.

3.2. Ejection. Aircraft passengers who suffered with variable dynamic impacts are easy to develop cervical spondylosis or disabilities. Despite the fact that the ejection seat and restraint system have been developed over the past years, the occurrence of ejection related to spinal injury still maintains high. Many contributing factors add to the risk of injury during ejection, including the impact of axial $(\mathrm{Gz})$ acceleration, the frequency of muscle endurance training, and the length of flight time [76]. Experimental work tends to be costly and well-prepared, while it just provides partial information concerning the reaction of the body under impact. Consequently, many research studies have focused on the mechanism of spinal cord injury emerged from impact loads or the use of numerical simulations to design protective devices [77].

The primary focus of the followings was to investigate the ejection trouble of the pilot. In 1958, Hess and Lombard [78] created the first continuum spinal model. In that model, the whole spine was regarded as a rod with homogeneous, linear elastic, free at the top, and a specified acceleration at the bottom. The most famous ejection model is the dynamic response index (DRI) model [6], which has been widely related to the data of injury and offers a helpful criterion for estimating safety under $\mathrm{Gz}$ acceleration. In ejection simulations, muscles need to be taken into account in order to better investigate the ejection mechanism. Soechting and Paslay [79] build a model to study the flexural response of the spine, which included spinal musculature effects. Since the global rigid dynamic models established in the previous studies could not provide the prediction of local stresses developed due to acceleration, Sadegh and Tchako [77] developed 3D FE models of the cervical spine capable of simulating the response of the neck muscular-skeletal structures when subjected to $\mathrm{Gz}$ acceleration forces during ejection.

Different ejection conditions may result in different cervical spine responses. Prasad and King [80] built a discrete human spine model to investigate the reaction of a pilot spine under a simulated vertical ejection. Teo et al. [81] used a detailed head-neck FE model, which had been previously validated, to study the effect of neck passive muscle strength on neck injury risk reduction during ejection. After the model was analyzed under a 10-G-ejection condition, it was further revealed that it is important for pilots to restrain muscle prior to ejection. According to the Life Mod, Song et al. [82] established a MB human-seat dynamic model to gain a deep insight into the mechanism of cervical injuries under various ejection environments.

Since both methods have different strong points and weak points in dealing with dynamic problems, their combination would contribute to investigate the spine in aviation conditions. Like the study of spine models for aviation safety by Kim [11], integrating the effect of the pilot belt, the FE model can provide more accurate analyses of the dynamic response of the spine after impact loading compared with the MB dynamics model.

3.3. Whiplash Injury. Whiplash and soft tissue sprains or strains of the cervical spine are the most frequent injuries in vehicle collisions, with nearly half of collision victims suffering this kind of injury $[83,84]$. Despite the efforts of numerous researchers, the causative mechanism of whiplash injuries is not fully understood. In the numerical simulation field, the FE method offers an effective way to study human tolerance and potential injuries under collisions, especially in the condition of whiplash injury.

Several research groups have investigated whiplash using computational models of the cervical spine for automotive research [58, 85-88]. The review of the development of MB models and FE models has been summarized in Tables 1 and 2. In this section, the literature covering the use of numerical models to predict whiplash injury has been reviewed. The summary of these models reviewed is provided in Table 3, which gives a brief overview of each model, the validated loadings, injuries studied, and references.

3.3.1. Ligaments. Ligaments are important soft tissues that have a certain effect on the whiplash injury. Since capsular ligament (CL) strain was recognized as one of the causes of prolonged pain for whiplash injury, Fice et al. [57] used the validated Panzer's model to simulate ligament strains for increasing rear impact severity. Their model was applied to research the distraction of ligaments and the probability of injury in the upper cervical spine. The simulation results showed that the upper cervical spine ligament strain increased with the increase of impact severity. The model proposed by Zhang was improved to incorporate the T1 vertebra [89] and, then, was used to investigate the cervical spine ligament tensions under different acceleration levels by applying different amplitude to the inferior $\mathrm{T} 1$ vertebral body. The results indicated that the peak impact acceleration plays an important role in the potential injury of the ligament. Cronin et al. [90] used a detailed numerical model to investigate the sources of pain generation under rear-end collisions. Ligament deformations are also considered as a mechanism causing whiplash injury. The model of human body (HUMOS) model developed by Tropiano et al. [87] was simulated to examine strain levels in ligaments and distinguish modes of injury. Obvious changes in soft tissue 
TABLe 3: Overview of numerical models to predict whiplash injury.

\begin{tabular}{|c|c|c|c|c|c|}
\hline $\begin{array}{l}\text { Model } \\
\text { name }\end{array}$ & Type & Description & Validated for & Injuries studied & References \\
\hline TNO neck & $\mathrm{MB}$ & $\begin{array}{l}\text { Skull to } \mathrm{T} 1 \\
\text { Vertebrae: rigid, scanned from cadaver } \\
\text { Ligaments: piecewise linear springs } \\
\text { Discs: 3D point restraint } \\
\text { Facets: 1D point restraint } \\
\text { Muscle: } 68 \text { passive pairs }\end{array}$ & $\begin{array}{l}\text { Quasistatic facet } \\
\text { response } \\
\text { All response } \\
\text { Rear impact }\end{array}$ & $\begin{array}{l}\text { ALL strain effect of posture of } \\
\text { CL strain }\end{array}$ & {$[26,85,86]$} \\
\hline HUMOS & $\mathrm{FE}$ & $\begin{array}{c}\text { Full body 50th percentile male in the seated } \\
\text { position } \\
\text { Approx. } 50,000 \text { elements } \\
\text { Vertebrae: solid elastoplastic } \\
\text { Ligaments: } 1 \mathrm{D} \text { nonlinear springs } \\
\text { Discs: solid elements, incompressible fluid for } \\
\text { nucleus, linear elastic for annulus } \\
\text { Facets: two layers of solid elements with } \\
\text { springs for CL } \\
\text { Muscles: passive, nonlinear springs for elastic } \\
\text { properties }\end{array}$ & $\begin{array}{l}\text { Quasistatic segment } \\
\text { response }\end{array}$ & Vertebral stresses & [87] \\
\hline THUMS & $\mathrm{FE}$ & $\begin{array}{c}\text { Full body 50th percentile male in the seated } \\
\text { position } \\
\text { Approx. 80,000 elements } \\
\text { Vertebrae: linear elastic solids } \\
\text { Ligaments: piecewise linear discrete } \\
\text { Facets: no cartilage, shell elements for CL } \\
\text { Discs: solid linear elastic } \\
\text { Muscles: passive, 1D discrete }\end{array}$ & $\begin{array}{l}\text { Quasistatic facet } \\
\text { response }\end{array}$ & $\begin{array}{l}\text { CL strains and NIC influence of } \\
\text { active head restraints }\end{array}$ & [58] \\
\hline ETH neck & $\mathrm{FE}$ & $\begin{array}{c}\text { Skull to } \mathrm{T} 1 \\
\text { Vertebrae: rigid } \\
\text { Ligaments, facets, and discs modeled } \\
\text { Muscles: 1D discrete, active Hill type }\end{array}$ & Rear impact & $\begin{array}{c}\text { Dynamic pressure spikes put } \\
\text { the DRG at risk }\end{array}$ & [88] \\
\hline
\end{tabular}

strains were observed at both the anterior and posterior cervical levels.

3.3.2. Muscles. Whiplash simulations [87, 89, 90] involve not only the response of the ligamentous spine model but also the predicting of musculature with active or passive. Neck muscles also play a significant role in studying the whiplash injury. In 2002, Yoshida and Tsutsumi [91] analyzed the causes of such injuries using a FE model that incorporated muscle actions. The FE analysis results were compared to experimental results from volunteers [93] subjected to rear-end collisions, and it was revealed that the actions of the muscles affected the neck behavior of a driver involved in a rear-end car crash. Sharma et al. [94] used a newly developed active human skeletal muscle FE model to analyze the impacts of active muscle contraction on occupant kinematics under rear-end collision [95]. Simulations of $4 \mathrm{~g}$ rear impacts on the model exhibited that the muscle activation level can mimic the biofidelic behaviour of humans during crash. Similarly, Yan et al. [92] investigated the influence of active muscle force during neck injury. It was found that the active force emerged by the neck muscles in low-speed collision is more significant compared to that in high-speed collision. Recently, de Bruijn et al. [93] modeled a detailed finite element model with the muscle response validated to investigate head and neck motion during impacts. An OpenSim head-and-neck model was improved by Cazzola et al. [94] to investigate loading on the cervical spine during rugby, and then, Mortensen et al. [95] also modified OpenSim musculoskeletal models of the neck to study the moment generation and movement capabilities of Hyoid muscles.

3.3.3. Cervical Curvature. Individual differences in cervical spine alignment of vehicle passengers are recognized to be a major factor for the high incidence of WAD in collision accidents. Studying the effect of spinal curvature on capsular ligament strains, the cervical lordosis curvature can be described as concave at the posterior surface, which is the normal curvature of a healthy individual. Stemper et al. [85] exposed their model to a simulated impact velocity of $2.6 \mathrm{~m} / \mathrm{s}$. The results demonstrated that, during a rear-impact, individuals with nonnormal spinal curvature were at a higher risk for sustaining CL injury, specifically in the lower cervical spine. In a separate study, Stemper et al. [86] employed the same model to predict anterior longitudinal ligament elongations during rear impact with up to $3.6 \mathrm{~m} / \mathrm{s}$ velocity change and concluded that whiplash injury mitigation can be achieved by minimizing head retraction early in the impact. Similar to the latter study, a female full cervical spine model was used to study the impact of diverse 
spinal curvatures of the same individual on the motions and mechanical parameters relevant to $\mathrm{WAD}$ in rear impacts. Recently, Sato et al. [96] indicated that both volunteers including male and female exhibited diverse spinal alignment when they were in the same seat. Based on the results of the research by Östh et al. [61], we can predict that the geometry of automotive seats contributes to females gaining a cervical spine alignment with more ligament strain related to the neutral posture, which could be an explanation that females have a higher WAD risk than males. Individual differences can be represented through the differences of cervical spine alignment. The head-neck finite element model was, then, performed according to images of typical cervical spine alignments from a hospital database to obtain multiple head-neck finite element models with five different cervical spine alignments [97]. Rearend impact analysis results showed that differences in the intervertebral rotation and ligament strain might be the cause of variability in the neck injury risk in rear-end impact accidents.

3.3.4. Head Restraints. The occupant's response is influenced by a lot of factors including impact severity and seat design, as well as gender and posture. The majority of current finite element models are concentrated on modeling the head and neck, neglecting the interaction of the seat with the occupant during rear collision. In the 1960s, the head restraint was proposed as a measure in order to deal with the whiplash injury. For investigating the influence of head restraint backset on cervical spine kinematics in whiplash, a parametric study for improving the head restraint backset through exercising the model in rear impact was conducted by Stemper et al. [98] with a MADYMO head-neck model. Kitagawa et al. [58] used the THUMBS (Total Human Model for Safety human body model) to investigate the impact of an active head restraint on CL strain and neck injury criteria (NIC). It was found that, during rear impact, the peak capsular strain was significantly reduced with the use of an active head restraint. It was concluded by both Stemper and Kitagawa that the active head restraint was effective in reducing the risk of whiplash injury. In 2005, Hassan et al. [62] developed a comprehensive head-neck FE model to present the whiplash phenomenon in a rear-end collision environment, and the influence of the headrest on head-neck complex responses was also considered. The results showed that proper headrest can effectively keep away from extension injury during the acceleration stage of cervical spine in whiplash. Later, the Global Human Body Model Consortium (GHBMC) finite element model was applied to investigate these interaction impacts with emphases on the effect of seat belt, headrest, and seat stiffness on the occupant's response during rear-end collisions [99]. The study specifically indicates seat belts and headrests can effectively reduce damage caused by rear collisions and reduce head displacement and rotation.

3.4. Vibration. Long-term exposure to vibration may cause irreparable physiological or perception damages. According to the scientific literature [100], FE models have been used in vibration investigations; however, there are limitations, since the modelling is often restricted to the two-dimensional behaviour in the sagittal plane or spine models are often limited to the lumbar vertebrae and lack the cervical ones. The main problem for simulating the human vibration behavior is to consider the motion structure of bones and joints combined with the flexibility of soft tissues. Both Kong and Goel [101] and Pennestrì et al. [102] talked about the ability of FE models to predict the human vibration behavior. Kong and Goel [101] compared a model of the whole spine (head-sacrum) and a partial model (thorax-sacrum) and explained slight differences. Pennestrì et al. [102] performed a comparison between the FE model and a simplified MB dynamics model. They concluded that MB models can simulate underlying behaviors of vibration with an effective complexity. In 2003, Gonçalves and Ambrósio [103] proposed the combination of a MB model with a transport in order to evaluate the comfort of passengers. Then, Valentini and Vita [104] proposed a more explicit 3D MB model applied for the combination proposed by Gonçalves and Ambrósio [103]. In the vibration environment, muscles should be also taken into consideration. Therefore, Bazrgari et al. [105] evaluated the effect of muscle forces on systemic vibration behavior. It was summarized that the muscle counter reaction activity is very important in the high vibration amplitude environment. The models mentioned above with the description of the whole spine can present dynamics of the cervical spine in an ideal methods, including local responses, as well as specific contribution [101-105].

\section{Conclusions}

Numerical simulations have become an important research method for investigating human injury biomechanics. This paper reviewed the development of different human cervical spine computational models, mainly, MB and FE models, including the establishment of model geometry and the validation process, especially the application of simulation models. The literature involved in this paper provides deep insights into the understanding of the cervical spine injury mechanisms and related treatment and prevention. Despite the fact that the study of the cervical spine using simulation methods is continuously developing, there are still things that are imperfect. Therefore, some suggestions for further investigations in model construct are given as follows:

In soft tissue modeling, most cervical spine models use $2 \mathrm{D}$ elements that the accurate anatomical features cannot be represented well. Developing more detailed and accurate 3D nonlinear models of soft tissues may contribute to truly predict of cervical spine responses. At present, the research in the field of vibration has been mainly focused on the lumbar vertebrae and not on the cervical spine. More efforts should be made to study, in depth, the mechanisms of damage based on cervical spine dynamics.

In future studies, new material properties should be considered in order to obtain accurate dynamic responses of the cervical spine. Schroeder et al. $[106,107]$ developed 
the "OVED model" (osmo-poro-visco-hyper-elastic disc), which has lay a solid foundation for the precise determination of the biomechanical environments in the IVD.

The implementation of these recommendations for the development of future models can help us to construct a more perfect finite element model of cervical vertebrae, thus improving the accuracy and computational efficiency of the model. We can have a deeper understanding of the mechanism of cervical spine injury.

\section{Abbreviations}

MB: Multibody

FE: $\quad$ Finite element

CL: Capsular ligament

WAD: Whiplash-associated disorders

2D: Two-dimensional

3D: Three-dimensional

IVD: Intervertebral disk

DOF: Degrees of freedom

AF: Annulus fibrosus

NP: Nucleus pulposus

EMG: Electromyography

DRI: Dynamic response index model.

\section{Additional Points}

Highlights. (1) Cervical vertebrae are the most vulnerable to trauma after impact. (2) Simulation methods are widely used in the study of cervical injury mechanisms. (3) Review on the development process of related simulation models. (4) Detailed study on the application of simulation models in cervical dynamics. (5) Development and further challenges of cervical dynamics research.

\section{Conflicts of Interest}

The authors declare that they have no conflicts of interest.

\section{Acknowledgments}

Financial support for this work was provided by the National Natural Science Foundation of China (NSFC Nos. 11432016, 11602172, 11602063, and 11802207), Sichuan Science and Technology Program (No. 2018SZ0036), and Fundamental Research Funds for Central Public Welfare Research Institutes (118009001000160001).

\section{References}

[1] Q. H. Zhang, E. C. Teo, and H. W. Ng, "Development and validation of A C0-C7 FE complex for biomechanical study," Journal of Biomechanical Engineering, vol. 127, no. 5, pp. 729-735, 2005.

[2] T. Mustafy, K. Moglo, S. Adeeb, and M. El-Rich, "Injury mechanisms of the ligamentous cervical C2-C3 functional spinal unit to complex loading modes: finite element study,"
Journal of the Mechanical Behavior of Biomedical Materials, vol. 53, pp. 384-396, 2016.

[3] M. Von Koch, A. Nygren, and C. Tingvall, "Validation of the new injury impairment scale (IIS)," in Proceedings of the Annual Proceedings of the Association for the Advancement of Automotive Medicine: Association for the Advancement of Automotive Medicine, pp. 123-138, Lyon, France, 1994.

[4] M. Avery, E. Giblen, A. Weekes, and D. Zuby, "Developments in dynamic whiplash assessment procedures," in Proceedings of the Conference on Neck Injuries in Road Traffic and Prevention Strategies, pp. 5-6, Munich, Germany, 2007.

[5] V. Esat and M. Acar, "Viscoelastic finite element analysis of the cervical intervertebral discs in conjunction with a multibody dynamic model of the human head and neck," Proceedings of the Institution of Mechanical Engineers, Part H: Journal of Engineering in Medicine, vol. 223, no. 2, pp. 249-262, 2009.

[6] M. de Jager, "Mathematical modeling of the human cervical spine: a survey of the literature," in Proceedings of the IRCOBI Conference on the Biomechanics of Impacts, Citeseer, Eindhoven, Netherlands, pp. 213-227, 1993.

[7] D. F. Huelke and G. S. Nusholtz, "Cervical spine biomechanics: a review of the literature," Journal of Orthopaedic Research, vol. 4, no. 2, pp. 232-245, 1986.

[8] M. M. Panjabi, "Cervical spine models for biomechanical research," Spine, vol. 23, no. 24, pp. 2684-2699, 1998.

[9] N. Yoganandan, S. Kumaresan, L. Voo, and F. A. Pintar, "Finite element applications in human cervical spine modeling," Spine, vol. 21, no. 15, pp. 1824-1834, 1996.

[10] M. J. Fagan, S. Julian, and A. M. Mohsen, "Finite element analysis in spine research," Proceedings of the Institution of Mechanical Engineers, Part H: Journal of Engineering in Medicine, vol. 216, no. 5, pp. 281-298, 2002.

[11] Y. H. Kim, B. Khuyagbaatar, K. Kim et al., "Recent advances in finite element modeling of the human cervical spine," Journal of Mechanical Science and Technology, vol. 32, no. 1, pp. 1-10, 2018.

[12] Z. Deng, K. Wang, H. Wang, T. Lan, H. Zhan, and W. Niu, "A finite element study of traditional Chinese cervical manipulation," European Spine Journal, vol. 26, no. 9, pp. 2308-2317, 2017

[13] C. Du, Z. Mo, S. Tian et al., "Biomechanical investigation of thoracolumbar spine in different postures during ejection using a combined finite element and multi-body approach," International Journal for Numerical Methods in Biomedical Engineering, vol. 30, no. 11, pp. 1121-1131.

[14] M. Panzer, Numerical Modelling of the Human Cervical Spine in Frontal Impact, University of Waterloo, Waterloo, Canada, 2006.

[15] J. Williams and T. Belytschko, "A Three-dimensional model of the human cervical spine for impact simulation," Journal of Biomechanical Engineering, vol. 105, no. 4, pp. 321-331, 1983.

[16] T. Merrill, W. Goldsmith, and Y. C. Deng, "Three-dimensional response of a lumped parameter head-neck model due to impact and impulsive loading," Journal of Biomechanics, vol. 17, no. 2, pp. 81-95, 1984.

[17] Y.-C. Deng and W. Goldsmith, "Response of a human head/ neck/upper-torso replica to dynamic loading-II. Analytical/ numerical model," Journal of Biomechanics, vol. 20, no. 5, pp. 487-497, 1987.

[18] L. Jakobsson, H. Norin, C. Jernström et al., "Analysis of different head and neck responses in rear-end car collisions using a new humanlike mathematical model," in Proceedings 
of the 1994 International Conference on the Biomechanics of Impact (IRCOBI), pp. 109-126, Lyon, France, 1994.

[19] D. M. Jager, A. F. Sauren, J. J. Thunnissen, and J. Wismans, "A global and a detailed mathematical model for head-neck dynamics," in Proceedings of the SAE Transactions, vol. 40, no. 6, pp. 269-281, Albuquerque, NM, USA, 1996.

[20] D. L. Camacho, R. W. Nightingale, J. J. Robinette, S. K. Vanguri, D. J. Coates, and B. S. Myers, "Experimental flexibility measurements for the development of a computational head-neck model validated for near-vertex head impact," in Proceedings of the SAE Technical Paper Series, pp. 3989-4002, 1997.

[21] A. Van den Kroonenberg, J. Thunnissen, and J. Wismans, "A human model for low-severity rear-impacts," in Proceedings of the 1997 International IRCOBI Conference, pp. 117-132, Hanover, Germany, 1997.

[22] K. Yamazaki, K. Ono, and K. Kaneoka, "A simulation analysis of human cervical spine motion during low speed rear-end impacts," in Proceedings of the SAE 2000 World Congress, Detroit, MI, USA, 2000.

[23] A. Linder, "A new mathematical neck model for a low-velocity rear-end impact dummy: evaluation of components influencing head kinematics," Accident Analysis \& Prevention, vol. 32, no. 2, pp. 261-269, 2000.

[24] M. Van Der Horst, Human Head Neck Response in Frontal, Lateral and Rear end Impact Loading: Modeling and Validation, Technische Universiteit Eindhoven, Eindhoven, Netherlands, 2002.

[25] I. Lee, H. Choi, J. Lee, and D. Han, "Development of finite element human neck model for vehicle safety simulation," International Journal of Automotive Technology, vol. 5, pp. 33-46, 2004.

[26] B. D. Stemper, N. Yoganandan, and F. A. Pintar, "Validation of a head-neck computer model for whiplash simulation," Medical \& Biological Engineering \& Computing, vol. 42, no. 3, pp. 333-338, 2004.

[27] D. W. van Lopik and M. Acar, "Development of a multi-body computational model of human head and neck," Proceedings of the Institution of Mechanical Engineers, Part K: Journal of Multi-Body Dynamics, vol. 221, no. 2, pp. 175-197, 2007.

[28] S. Himmetoglu, M. Acar, K. Bouazza-Marouf, and A. Taylor, "A multi-body human model for rear-impact simulation," Proceedings of the Institution of Mechanical Engineers, Part D: Journal of Automobile Engineering, vol. 223, no. 5, pp. 623-638, 2009.

[29] E. de Bruijn, F. C. T. Van der Helm, and R. Happee, “Analysis of isometric cervical strength with a nonlinear musculoskeletal model with 48 degrees of freedom," Multibody System Dynamics, vol. 36, no. 4, pp. 339-362, 2016.

[30] D. Cazzola, T. P. Holsgrove, E. Preatoni et al., "Cervical spine injuries: a whole-body musculoskeletal model for the analysis of spinal loading," PLoS One, vol. 12, no. 1, Article ID e0169329, 2017.

[31] J. D. Mortensen, A. N. Vasavada, and A. S. Merryweather, "The inclusion of hyoid muscles improve moment generating capacity and dynamic simulations in musculoskeletal models of the head and neck," PLoS One, vol. 13, no. 6, Article ID e0199912, 2018.

[32] A. Linder and M. Y. Svensson, "BioRID, a crash test dummy for rear impact: a review of development, validation and evaluation," in Proceedings of the Road Safety Research, Policing and Education Conference, Brisbane, Queensland, Australia, 2000.
[33] M. Y. Svensson and P. Lövsund, "A dummy for rear-end collisions: development and validation of a new dummy neck," in Proceedings of the 1992 International IRCOBI Conference on the Biomechanics of Impacts, pp. 299-310, Verona, Italy, 1992.

[34] V. Esat and M. Acar, "A multi-body human spine model for dynamic analysis in conjunction with the FE analysis of spinal parts," in Proceedings of 1st Annual Injury Biomechanics Symposium, The Ohio State University, 2005.

[35] V. Esat and M. Acar, "A multi-body model of the whole human spine for whiplash investigations," in Proceedings of the 20th Enhanced Safety of Vehicles Conference: Innovations for Safety: Opportunities and Challenges, Lyon, France, 2007.

[36] S. Himmetoglu, M. Acar, A. J. Taylor, and K. BouazzaMarouf, "A multi-body head-and-neck model for simulation of rear impact in cars," Proceedings of the Institution of Mechanical Engineers, Part D: Journal of Automobile Engineering, vol. 221, no. 5, pp. 527-541, 2007.

[37] J. Y. Rho, M. C. Hobatho, and R. B. Ashman, "Relations of mechanical properties to density and CT numbers in human bone," Medical Engineering \& Physics, vol. 17, no. 5, pp. 347-355, 1995.

[38] M. Lengsfeld, J. Schmitt, P. Alter, J. Kaminsky, and R. Leppek, "Comparison of geometry-based and CT voxelbased finite element modelling and experimental validation," Medical Engineering \& Physics, vol. 20, no. 7, pp. 515-522, 1998.

[39] G. Chen, B. Schmutz, D. Epari et al., "A new approach for assigning bone material properties from CT images into finite element models," Journal of Biomechanics, vol. 43, no. 5, pp. 1011-1015, 2010.

[40] B. A. Christiansen, D. L. Kopperdahl, D. P. Kiel, T. M. Keaveny, and M. L. Bouxsein, "Mechanical contributions of the cortical and trabecular compartments contribute to differences in age-related changes in vertebral body strength in men and women assessed by QCT-based finite element analysis," Journal of Bone and Mineral Research, vol. 26, no. 5, pp. 974-983, 2011.

[41] C. Zannoni, R. Mantovani, and M. Viceconti, "Material properties assignment to finite element models of bone structures: a new method," Medical Engineering \& Physics, vol. 20, pp. 735-740, 1998.

[42] D. L. Kopperdahl, E. F. Morgan, and T. M. Keaveny, "Quantitative computed tomography estimates of the mechanical properties of human vertebral trabecular bone," Journal of Orthopaedic Research, vol. 20, no. 4, pp. 801-805, 2002.

[43] M. C. Hobatho, J. Y. Rho, and R. B. Ashman, "Anatomical variation of human cancellous bone mechanical properties in vitro," Studies in Health Technology and Informatics, vol. 40, pp. 157-173, 1997.

[44] C.-X. Yuchi, G. Sun, C. Chen et al., "Comparison of the biomechanical changes after percutaneous full-endoscopic anterior cervical discectomy versus posterior cervical foraminotomy at C5-C6: a finite element-based study," World Neurosurgery, vol. 128, pp. e905-e911, 2019.

[45] X.-Y. Cai, D. Sang, C.-X. Yuchi et al., "Using finite element analysis to determine effects of the motion loading method on facet joint forces after cervical disc degeneration," Computers in Biology and Medicine, vol. 116, Article ID 103519, 2019.

[46] C.-F. Du, X.-Y. Cai, and M.-S. Sun, "The biomechanical response of cervical spine under different follower loads," in Proceedings of the 2019 IEEE International Conference on 
Mechatronics and Automation (ICMA), pp. 360-364, IEEE, Tianjin, China, August 2019.

[47] C.-F. Du, C.-X. Yuchi, X.-Y. Cai, and M.-S. Sun, "A finite element analysis of anterior cervical discectomy and fusion compared with percutaneous full-endoscopic anterior cervical discectomy," in Proceedings of the 2019 IEEE International Conference on Mechatronics and Automation (ICMA), pp. 1311-1315, IEEE, Tianjin, China, August 2019.

[48] C.-F. Du, M.-S. Sun, X.-Y. Cai, and C.-X. Yuchi, "Biomechanical comparison of lateral interbody fusion with and without fixation," in Proceedings of the 2019 IEEE International Conference on Mechatronics and Automation (ICMA), pp. 377-381, IEEE, Tianjin, China, August 2019.

[49] Q. H. Zhang and E. C. Teo, "Finite element application in implant research for treatment of lumbar degenerative disc disease," Medical Engineering \& Physics, vol. 30, no. 10, pp. 1246-1256, 2008.

[50] M. Kleinberger, "Application of finite element techniques to the study of cervical spine mechanics," in Proceedings of the SAE Technical Paper Series, Traverse City, MI, USA, 1993.

[51] F. Dauvilliers, F. Bendjellal, M. Weiss, F. Lavaste, and C. Tarriere, "Development of a finite element model of the neck," in Proceedings of the SAE Transactions, pp. 1645-1659, 1994.

[52] K. H. Yang, F. Zhu, F. Luan, L. Zhao, and P. C. Begeman, "Development of a finite element model of the human neck," in Proceedings of the SAE Technical Paper, Tempe, AZ, USA, 1998.

[53] Y.-C. Deng, X. Li, and Y. Liu, "Modeling of the human cervical spine using finite element techniques," in Proceedings of the SAE Technical Paper, Detroit, MI, USA, 1999.

[54] P. Halldin and K. Brolin, "Investigation of conditions that affect neck compression-flexion injuries using numerical techniques," in Proceedings of the SAE Technical Paper, Atlanta, GA, USA, 2000.

[55] J. Yang and J. Yao, "Development and validation of a human neck FE model in impact loading condition," Journal of Hunan University (Natural Sciences Edition), vol. 30, pp. 40-46, 2003.

[56] F. Meyer, N. Bourdet, C. Deck, R. Willinger, and J. Raul, "Human neck finite element model development and validation against original experimental data," in Proceedings of the SAE Technical Paper, Nashville, TN, USA, 2004.

[57] J. B. Fice, D. S. Cronin, and M. B. Panzer, "Cervical spine model to predict capsular ligament response in rear impact," Annals of Biomedical Engineering, vol. 39, no. 8, pp. 21522162, 2011.

[58] Y. Kitagawa, T. Yasuki, and J. Hasegawa, "Research study on neck injury lessening with active head restraint using human body FE model," Traffic Injury Prevention, vol. 9, no. 6, pp. 574-582, 2008.

[59] M. B. Panzer, J. B. Fice, and D. S. Cronin, "Cervical spine response in frontal crash," Medical Engineering \& Physics, vol. 33, no. 9, pp. 1147-1159, 2011.

[60] D. Cronin, J. Fice, J. DeWit, and J. Moulton, "Upper cervical spine kinematic response and injury prediction," in Proceedings of the IRCOBI Conference, pp. 225-234, Dublin, Ireland, September 2012.

[61] J. Östh, M. Mendoza-Vazquez, F. Sato, M. Y. Svensson, A. Linder, and K. Brolin, "A female head-neck model for rear impact simulations," Journal of Biomechanics, vol. 51, pp. 49-56, 2017.

[62] M. T. Z. Hassan and S. A. Meguid, "Effect of seat belt and head restraint on occupant's response during rear-end collision," International Journal of Mechanics and Materials in Design, vol. 14, no. 2, pp. 231-242, 2018.

[63] B. Jiayi, Z. Qianxiang, W. Xingwei et al., "Simulation and analysis of human neck load and injury during sustaining overload in flight," in Proceedings of the Congress of the International Ergonomics Association, Springer, pp. 86-95, Cham, Switzerland, 2018.

[64] K. Brolin and P. Halldin, "Development of a finite element model of the upper cervical spine and a parameter study of ligament characteristics," Spine, vol. 29, no. 4, pp. 376-385, 2004.

[65] K. Brolin, P. Halldin, and I. Leijonhufvud, "The effect of muscle activation on neck response," Traffic Injury Prevention, vol. 6 , no. 1, pp. 67-76, 2005.

[66] J. Yang, W. Xu, and X. Wan, "Development and validation of a head-neck finite element model for the study of neck dynamic responses in car impacts," Journal of Hunan University (Natural Sciences), vol. 32, pp. 6-12, 2005.

[67] S. F. E. Mattucci, J. A. Moulton, N. Chandrashekar, and D. S. Cronin, "Strain rate dependent properties of younger human cervical spine ligaments," Journal of the Mechanical Behavior of Biomedical Materials, vol. 10, pp. 216-226, 2012.

[68] T. B. W. Carstensen, L. Frostholm, E. Oernboel et al., "Are there gender differences in coping with neck pain following acute whiplash trauma? A 12-month follow-up study," European Journal of Pain, vol. 16, no. 1, pp. 49-60, 2012.

[69] M. Krafft, A. Kullgren, A. Lie, and C. Tingvall, "The risk of whiplash injury in the rear seat compared to the front seat in rear impacts," Traffic Injury Prevention, vol. 4, no. 2, pp. 136-140, 2003.

[70] J. Östh, K. Brolin, M. Y. Svensson, and A. Linder, "A female ligamentous cervical spine finite element model validated for physiological loads," Journal of Biomechanical Engineering, vol. 138, Article ID 061005, 2016.

[71] Q. H. Zhang, S. H. Tan, and E. C. Teo, "A numerical study of the effect of axial acceleration on the responses of the cervical spine during low-speed rear-end impact," Proceedings of the Institution of Mechanical Engineers, Part H: Journal of Engineering in Medicine, vol. 222, no. 7, pp. 1167-1174, 2008.

[72] T. Mustafy, M. El-Rich, W. Mesfar, and K. Moglo, "Investigation of impact loading rate effects on the ligamentous cervical spinal load-partitioning using finite element model of functional spinal unit C2-C3," Journal of Biomechanics, vol. 47, no. 12, pp. 2891-2903, 2014.

[73] C.-K. Lee, Y. Eun Kim, C.-S. Lee, Y.-M. Hong, J.-M. Jung, and V. K. Goel, "Impact response of the intervertebral disc in a finite-element model," Spine, vol. 25, no. 19, pp. 2431-2439, 2000.

[74] N. A. White, K. A. Danelson, F. Scott Gayzik, and J. D. Stitzel, "Head and neck response of a finite element anthropomorphic test device and human body model during a simulated rotary-wing aircraft impact," Journal of Biomechanical Engineering, vol. 136, no. 11, 2014.

[75] S. Hedenstierna, P. Halldin, and G. P. Siegmund, "Neck muscle load distribution in lateral, frontal, and rear-end impacts," Spine, vol. 34, no. 24, pp. 2626-2633, 2009.

[76] R. S. Salzar, J. R. Bolton, J. R. Crandall, G. R. Paskoff, and B. S. Shender, "Ejection injury to the spine in small aviators: sled tests of manikins vs. post mortem specimens," Aviation, Space, and Environmental Medicine, vol. 80, no. 7, pp. 621628, 2009.

[77] A. M. Sadegh and A. Tchako, "Vertebral stress of a cervical spine model under dynamic load," Technology and Health Care, vol. 8, no. 2, pp. 143-154, 2000. 
[78] J. L. Hess and C. F. Lombard, "Theoretical investigations of dynamic response of man to high vertical accelerations," The Journal of Aviation Medicine, vol. 29, no. 1, pp. 66-75, 1958.

[79] J. F. Soechting and P. R. Paslay, "A model for the human spine during impact including musculature influence," Journal of Biomechanics, vol. 6, no. 2, pp. 195-203, 1973.

[80] P. Prasad and A. I. King, "An experimentally validated dynamic model of the spine," Journal of Applied Mechanics, vol. 41, no. 3, pp. 546-550, 1974.

[81] E.-C. Teo, Q.-H. Zhang, K.-W. Tan, and V.-S. Lee, "Effect of muscles activation on head-neck complex under simulated ejection," Journal of Musculoskeletal Research, vol. 8, no. 4, pp. 155-165, 2004.

[82] R.-Z. Song, S.-F. Suo, X.-H. Jia, Y. Liu, and S.-Y. Liu, "Research on head-neck injuries of pilots during emergency ejection from the aircraft," Journal of Physics: Conference Series, vol. 1213, Article ID 052100, 2019.

[83] C. S. B. Galasko, P. M. Murray, M. Pitcher et al., "Neck sprains after road traffic accidents: a modern epidemic," Injury, vol. 24, no. 3, pp. 155-157, 1993.

[84] K. P. Quinlan, J. L. Annest, B. Myers, G. Ryan, and H. Hill, "Neck strains and sprains among motor vehicle occupants-United States, 2000," Accident Analysis \& Prevention, vol. 36, no. 1, pp. 21-27, 2004.

[85] B. D. Stemper, N. Yoganandan, and F. A. Pintar, "Effects of abnormal posture on capsular ligament elongations in a computational model subjected to whiplash loading," Journal of Biomechanics, vol. 38, no. 6, pp. 1313-1323, 2005.

[86] B. D. Stemper, N. Yoganandan, F. A. Pintar, and R. D. Rao, "Anterior longitudinal ligament injuries in whiplash may lead to cervical instability," Medical Engineering \& Physics, vol. 28, no. 6, pp. 515-524, 2006.

[87] P. Tropiano, L. Thollon, P. J. Arnoux et al., "Using a finite element model to evaluate human injuries application to the HUMOS model in whiplash situation," Spine, vol. 29, no. 16, pp. 1709-1716, 2004.

[88] K.-U. Schmitt, M. Muser, P. Niederer, and F. Walz, "Pressure aberrations inside the spinal canal during rear-end impact," Pain Research and Management, vol. 8, no. 2, pp. 86-92, 2003.

[89] Q. H. Zhang, E. C. Teo, H. W. Ng, and V. S. Lee, "Finite element analysis of moment-rotation relationships for human cervical spine," Journal of Biomechanics, vol. 39, no. 1, pp. 189-193, 2006.

[90] D. S. Cronin, "Finite element modeling of potential cervical spine pain sources in neutral position low speed rear impact," Journal of the Mechanical Behavior of Biomedical Materials, vol. 33, pp. 55-66, 2014.

[91] H. Yoshida and S. Tsutsumi, "Finite element analysis using muscles elements and experimental analysis with a new flexible neck model of whiplash injuries in rear-end collisions," in Proceedings of the SAE Technical Paper, Detroit, MI, USA, 2002.

[92] Y. Yan, J. Huang, F. Li, and L. Hu, "Investigation of the effect of neck muscle active force on whiplash injury of the cervical spine," Applied Bionics and Biomechanics, vol. 2018, Article ID 4542750, 10 pages, 2018.

[93] J. Davidsson, C. Deutscher, W. Hell, P. Lövsund, and M. Y. Svensson, "Human volunteer kinematics in rear-end sled collisions," Journal of Crash Prevention and Injury Control, vol. 2, no. 4, pp. 319-333, 2001.

[94] N. N. Sharma, J. Carmai, S. Koetniyom, and B. Markert, "Effects of active muscle contraction on whiplash injury," PAMM, vol. 16, no. 1, pp. 105-106, 2016.
[95] T. Maeno and J. Hasegawa, "Development of a finite element model of the total human model for safety (THUMS) and application to car-pedestrian impacts," in Proceedings of the SAE Technical Paper, Traverse City, MI, USA, 2001.

[96] F. Sato, T. Nakajima, K. Ono, M. Svensson, and K. Kaneoka, "Characteristics of dynamic cervical vertebral kinematics for female and male volunteers in low-speed rear impact, based on quasistatic neck kinematics," in Proceedings of the International Research Council on the Biomechanics of Impact (IRCOBI), pp. 9-11, Lyon, France, September 2015.

[97] J. A. Pramudita, S. Kikuchi, I. Minato, and Y. Tanabe, "Effect of cervical spine alignment on neck injury risk during rearend impact-numerical study using neck finite element model," International Journal of Crashworthiness, vol. 22, no. 4, pp. 453-466, 2017.

[98] B. D. Stemper, N. Yoganandan, and F. A. Pintar, "Effect of head restraint backset on head-neck kinematics in whiplash," Accident Analysis \& Prevention, vol. 38, no. 2, pp. 317-323, 2006.

[99] E.-C. Teo, Q.-H. Zhang, and H.-W. Ng, "Finite element analysis of head-neck responses during whiplash," Journal of Musculoskeletal Research, vol. 9, no. 1, pp. 1-7, 2005.

[100] P. P. Valentini and E. Pennestrì, "An improved three-dimensional multibody model of the human spine for vibrational investigations," Multibody System Dynamics, vol. 36, no. 4, pp. 363-375, 2016.

[101] W. Z. Kong and V. K. Goel, "Ability of the finite element models to predict response of the human spine to sinusoidal vertical vibration," Spine, vol. 28, no. 17, pp. 1961-1967, 2003.

[102] E. Pennestrì, P. Valentini, and L. Vita, "Comfort analysis of car occupant: comparison between multibody and finite element models," International Journal of Vehicle Systems Modelling and Testing, vol. 1, no. 1-3, p. 68, 2005.

[103] J. P. Gonçalves and J. A. Ambrósio, "Optimal comfort response of road vehicles using flexible multibody dynamics," in Proceedings of the ASME 2003 International Design Engineering Technical Conferences and Computers and Information in Engineering Conference: American Society of Mechanical Engineers (ASME), pp. 431-438, Chicago, IL, USA, 2003.

[104] P. Valentini and L. Vita, "David-a multybody virtual dummy for vibrational comfort analysis of car occupants," Virtual Nonlinear Multibody Systems, pp. 253-262, Springer, Berlin, Germany, 2003.

[105] B. Bazrgari, A. Shirazi-Adl, and M. Kasra, "Seated whole body vibrations with high-magnitude accelerations-relative roles of inertia and muscle forces," Journal of Biomechanics, vol. 41, no. 12, pp. 2639-2646, 2008.

[106] Y. Schroeder, J. M. Huyghe, C. C. Van Donkelaar, and K. Ito, "A biochemical/biophysical 3D FE intervertebral disc model," Biomechanics and Modeling in Mechanobiology, vol. 9, no. 5, pp. 641-650, 2010.

[107] Y. Schroeder, W. Wilson, J. M. Huyghe, and F. P. T. Baaijens, "Osmoviscoelastic finite element model of the intervertebral disc," European Spine Journal, vol. 15, no. S3, pp. 361-371, 2006. 